OPEN ACCESS

Edited by:

Paolo Moroni,

Cornell University, United States

Reviewed by:

Getahun E. Agga,

United States Department of

Agriculture, United States

Petr Sláma,

Mendel University in Brno, Czechia

*Correspondence:

Pamela L. Ruegg

plruegg@msu.edu

Specialty section:

This article was submitted to

Veterinary Infectious Diseases,

a section of the journal

Frontiers in Veterinary Science

Received: 09 December 2020

Accepted: 08 January 2021

Published: 02 February 2021

Citation:

Ruegg PL (2021) What Is Success? A Narrative Review of Research

Evaluating Outcomes of Antibiotics Used for Treatment of Clinical Mastitis.

Front. Vet. Sci. 8:639641

doi: 10.3389/fvets.2021.639641

\section{What Is Success? A Narrative Review of Research Evaluating Outcomes of Antibiotics Used for Treatment of Clinical Mastitis}

\author{
Pamela L. Ruegg* \\ David J. Ellis Chair in Antimicrobial Resistance \& Professor of Large Animal Clinical Sciences, College of Veterinary Medicine,
} Michigan State University, East Lansing, MI, United States

Treatment of clinical mastitis is the most common reason that antimicrobials are given to adult dairy cows and careful consideration of treatment protocols is necessary to ensure responsible antimicrobial stewardship. Clinical mastitis is caused by a variety of bacteria which stimulate an immune response that often results in spontaneous bacteriological clearance but can develop into long-term subclinical infections. Use of antimicrobial therapy is most beneficial for cases that are caused by pathogens that have a low rate of spontaneous cure but high rate of therapeutic cure. The purpose of this paper is to review studies that evaluated outcomes of antimicrobial therapy of clinical mastitis. Few studies reported differences in bacteriological cure among treatments and this outcome was rarely associated with clinical outcomes. Return to normal milk appearance was evaluated in most studies but demonstrated little variation and is not a reliable indicator of therapeutic success. Somatic cell count should be measured at quarter-level and will decline gradually after bacteriological clearance. Few researchers have evaluated important clinical outcomes such as post-treatment milk yield or culling. Few differences among approved antimicrobial therapies have been demonstrated and selection of antimicrobial therapy should consider the spectrum of activity relative to etiology.

Keywords: dairy, antibiotics, bacteria, veterinary, mastitis

\section{INTRODUCTION}

Mastitis is the most common bacterial disease of mature dairy cows (1-3) and is diagnosed based on recognition of an inflammatory response initiated after the immune system detects intramammary infection (IMI). Like most bacterial diseases, the magnitude of the inflammatory response is dependent on virulence of the pathogen and is regulated by the ability of the host to mount a rapid and effective immune response (4). A mild inflammatory response results in an influx of neutrophils into the gland without any visible changes in the gland (subclinical disease) whereas a larger inflammatory response results in observable localized or generalized signs (clinical mastitis). Subclinical mastitis is the most common outcome of IMI and is defined by enumeration of somatic cells in milk. When somatic cell count (SCC) of milk exceeds a healthy threshold (usually $>150,000$ or 200,000 cells $/ \mathrm{mL}$ ) (5) the gland is considered to be subclinically infected. Milk of cows affected with subclinical mastitis has a normal appearance and can be co-mingled with milk from healthy cows and sold for consumption, so treatment of subclinical mastitis during lactation is rarely recommended $(6,7)$. 
Clinical mastitis is diagnosed when the magnitude of the inflammatory response is sufficient to result in visible changes in the milk, the mammary gland or the cow. The incidence of clinical mastitis is estimated to range between about 17-40 cases per 100 cows per year (8-12). Clinical mastitis is often assessed based on severity of the presenting signs and only a small proportion of cows have acute systemic disease that requires immediate therapy (13-16). The appearance of clinical signs and the necessity of discarding abnormal milk results in strong motivation for farmers to effectively treat clinical cases (17). In the U.S., most cases of are treated with IMM products containing 1st or 3rd generation IMM cephalosporins without knowledge of etiology (8). Selection of antimicrobials was reported to be based on "historical effectiveness" (92\% of farmers), "veterinary recommendation" (66\%), "historical culture and sensitivity results," (33\%) or individual cow culture before treatment $(22 \%)$. The definition of "historical effectiveness" was not supplied and is illustrative of the ambiguities associated with evaluation of mastitis treatments. Oliveira et al. (18) reported treatment of 589 cases of clinical mastitis occurring on 51 Wisconsin dairy farms. Most cases were treated solely with IMM antibiotics but about $30 \%$ received either a second IMM antibiotic or were treated with both IMM and systemic antibiotics. In that study, farmers collected milk samples before treatment and later submitted them to a research laboratory. The culture results demonstrated that $32 \%$ of IMM antibiotics were administered to clinical cases that were bacteriologically negative before treatment and an additional 19\% of IMM antibiotics were given to cases caused by E. coli. In these herds, symptomatic treatment of non-severe cases of clinical mastitis without determination of etiology resulted in over-prescription of antibiotics in almost $50 \%$ of cases. More recently, treatment data was reported for $>26,000$ cases of clinical mastitis occurring on 40 large Wisconsin dairy herds $(2,19)$. Based on review of computerized health records, the incidence of clinical mastitis on these farms was $34 \%$ and use of antimicrobials varied greatly. About $31 \%$ of cases were not treated using antimicrobials, while $53 \%$ received approved products containing IMM ceftiofur, 10\% received IMM cephapirin, 3\% each were treated with IMM hetacillin or pirlimycin and $<1 \%$ received IMM amoxicillin. Systemic antibiotics were given to $14 \%$ of cases on 29 farms. The average duration of treatment using IMM antibiotics ranged from 3.3 to $5.7 \mathrm{~d}$. There was no indication that efficacy varied among treatments.

Symptomatic treatment without knowledge of etiology results in unnecessary antimicrobial treatments (such as use of antimicrobials for treatment of culture negative cases) (18) and it is impossible to determine etiology without use of diagnostic tests (such as culturing or DNA based technologies). Knowledge of etiology is fundamental to prescribe an appropriate treatment and is necessary to properly evaluate outcomes. Pathogens vary in virulence and possess differing abilities to stimulate an immune response that may result in spontaneous bacteriological cure. Differences in bacterial cell wall structures result in differing susceptibilities to antimicrobials, and most antibiotics approved for treatment of mastitis have limited ability to inhibit or destroy Gram-negative bacteria. Exposure to mastitis pathogens varies among herds but overall, the distribution of etiologies on modern dairy farms is fairly consistent. When milk samples from quarters affected with clinical mastitis are properly collected and assessed, the results are typically distributed as no growth (15-30\%), Gram-negative (20-30\%), gram-positive (20-25\%), and 10$15 \%$ other pathogens (Prototheca spp, Serratia spp., yeasts and others) $(3,10,12,18,20,21)$. While there are some exceptions, it is difficult to justify the use of antimicrobial therapy for treatment of non-severe cases of clinical mastitis that are culture negative $(15,16,22-24)$ or Gram-negative (25-27) and inclusion of these cases in positively controlled efficacy studies may result in over-estimating the impact of antimicrobial therapy. Thus, pathogen-specific evaluation of therapeutic outcomes is strongly recommended.

Use of culture-based protocols to guide selective therapy have been shown to be cost effective and result in more judicious antimicrobial usage $(16,24,28)$ but some researchers have created economic models suggesting that delayed therapy may have negative consequences for herds that have a significant proportion of clinical mastitis caused by Grampositive organisms (29). Recommendations for treatment are frequently based on outcomes defined in clinical trials but relatively few clinical trials have been performed to generate evidence based protocols. On farms, treatment efficacy is often judged by the speed of return to normal appearance of milk, but this outcome has little variation and is not a good indicator of therapeutic success (30) so an understanding of the importance of other outcomes is needed. The purpose of this paper is to review clinical trials that were conducted to assess antimicrobial treatments of clinical mastitis and discuss the strengths and limitations of outcomes used to evaluate therapeutic success.

\section{CONSIDERATIONS WHEN EVALUATING MASTITIS TREATMENTS}

\section{Spectrum of Activity}

When evaluating outcomes of mastitis therapy, the spectrum of activity of the antimicrobial should be considered relative to the etiology of the cases enrolled in the study. In most countries, a variety of IMM antimicrobials are approved and veterinarians in some countries have access to systemically administered drugs that are able to penetrate mammary gland barriers (21). Most approved antimicrobials are relatively narrow spectrum (target Gram-positive organisms) but in some countries, broader spectrum products such as 3rd and 4th generation cephalosporins and some quinolones are approved. Dairy farmers in the U.S. have access to 7 approved IMM antimicrobial products but no systemic products are approved for treatment of clinical mastitis (limited extralabel usage of some products is allowed). One approved IMM product is classified as a lincosamide (pirlimycin) while 6 IMM products are classified as beta-lactams. The beta-lactams include 1st (cephapirin) and 3rd (ceftiofur) generation cephalosporins, aminopenicillins (amoxicillin and hetacillin), penicillin $\mathrm{G}$, and a penicillinase-resistant penicillin (cloxacillin) (31). All approved IMM products are expected to have efficacy against most common Gram-positive mastitis pathogens and most are labeled 
as efficacious against Streptococci and Staphylococci. While there is limited research to differentiate among products, based on the antimicrobial classes, it is unlikely that there are significant differences among approved IMM products in efficacy for treatment of common Gram-positive pathogens. Use of antimicrobials for treatment of non-severe mastitis caused by $E$. coli is generally not needed (26) because these cases have a high rate of spontaneous cure $(25,26)$, thus very few cases of clinical mastitis benefit from use of a broader spectrum antimicrobials.

\section{Intrinsic and Acquired Resistance}

Before antimicrobials are approved for treatment of mastitis they are required to demonstrate efficacy for pathogens that are listed on the product label. Before antimicrobials are used to treat pathogens that are not listed on the label, the possibility of intrinsic resistance should be considered. Intrinsic resistance occurs when a bacterial genus or species lacks targets or possess defenses to render an antimicrobial ineffective. For example, Gram-negative bacteria are intrinsically resistant to pirlimycin because their cell walls lack a binding site. Most Gramnegative bacteria are intrinsically resistant to penicillin $G$, many Klebsiella spp. are intrinsically resistant to aminopencillins and intrinsic resistance to ampicillin and 1st and 2nd generation cephalosporins are common in Enterobacter spp. (32). Two IMM products (ceftiofur and hetacillin) have label claims that include efficacy for $E$. coli, but no products have efficacy claims for treatment of mastitis caused by Klebsiella spp. Some studies evaluating antimicrobial therapies of mastitis have included cases that are intrinsically resistant to the product $(33,34)$ and in these instances outcomes cannot be attributed to antimicrobial therapy. Knowledge of etiology is necessary to ensure that the spectrum of activity of an antimicrobial is appropriate for the case.

Acquired resistance refers to acquisition of resistance by a normally susceptible bacterial strain through some kind of genetic modification and is usually recognized by bi-modal distribution of minimum inhibitory concentration (MIC) values. Monitoring acquired resistance is useful to identify the potential of transmission of genetic determinants of resistance into environments and food systems. While there is little evidence that most mastitis pathogens found in N. American dairy herds have acquired widespread resistance to most IMM antimicrobials (35), a bimodal distribution of MIC values was observed for about one-third of Klebsiella pneumoniae included in a recent trial (25) and susceptibility of pathogens that are not included on product labels should be monitored on a regular basis.

\section{Accounting for Cow Factors}

Therapeutic success is driven by both pathogen factors and cow characteristics $(30,36-38)$. Effective bacterial clearance depends on a robust immune response and factors such as parity, stage of lactation, and history of previous clinical or subclinical mastitis cases should be considered when evaluating efficacy of treatments administered for clinical mastitis.

\section{METHODS USED TO EVALUATE RESEARCH ABOUT CLINICAL MASTITIS TREATMENT}

\section{Inclusion of Trials in This Review}

Studies included in this review were retrieved by searching databases and web platforms using PubMed, Web of Science, and Google Scholar. Addition studies were added by reviewing bibliographies of relevant papers. Boolean search terms were used and included mastitis, bovine, clinical, randomized, non-inferiority and treatment. Only natural exposure clinical trials that utilized randomized or systematic allocation to evaluate antimicrobial treatments and were published since 2000 in English language journals were retrieved. Only studies from the last 20 years were included because there have been considerable changes in the distribution of pathogen from contagious organisms (such as $S$. aureus and $S$. agalactiae), to a more diverse mix of environmental organisms (5), use of antimicrobials is increasingly discouraged and management of clinical mastitis has gradually shifted to selective therapy of clinical cases using on-farm culture.

Studies that did not define the antimicrobial therapy or included only non-antimicrobial therapies were excluded. Studies evaluating homeopathic or herbal treatments were also excluded. While thorough, the search was not systematic and although no studies that met inclusion criteria were excluded, it is likely that some qualifying studies were missed.

Despite the global importance of bovine mastitis, relatively few clinical trials that evaluated antimicrobial treatments of clinical mastitis were identified (Table 1). While a systematic review or meta-analysis is the ideal method to summarize and compare studies, the wide diversity of study designs, variation in outcomes, differences in pathogens and treatment protocols included in mastitis trials creates a challenging situation relative to use of this method. The limited number of trials evaluating antimicrobial therapy used for treatment of bovine mastitis has been previously noted by authors of a systematic review who were unable to identify sufficient papers to establish networks to evaluate bacteriological cure and were unable to reach a conclusion about clinical efficacy of antimicrobials (59). Studies included in this review were conducted in the U.S. or Canada $(n=9)$, European Union $(n=8)$, New Zealand $(n=6)$, Brazil $(n=2)$ and Mexico $(n=1)$. The 26 studies included 65 study arms that included IMM therapy containing a single antimicrobial $(n=28)$, IMM therapy containing combination products $[n(60)=13]$, combined IMM and systemic therapy $(n=5)$, systemic therapy only $(n=11)$, non-antibiotic treatments $(n=2)$ and no treatment (negative control; $n=6$ ). Antibiotic classes included penicillins and extended spectrum penicillins, penicillin and aminoglycoside combinations, 1st-4th generation cephalosporins, lincosamides, a lincosamide combined with an aminoglycoside, tetracycline combined with several other classes, fluoroquinolones and macrolides. No studies were replicated, and a variety of outcomes were reported. 
TABLE 1 | Description of 26 clinical mastitis treatment trials published since 2000 and meeting inclusion criteria for this review.

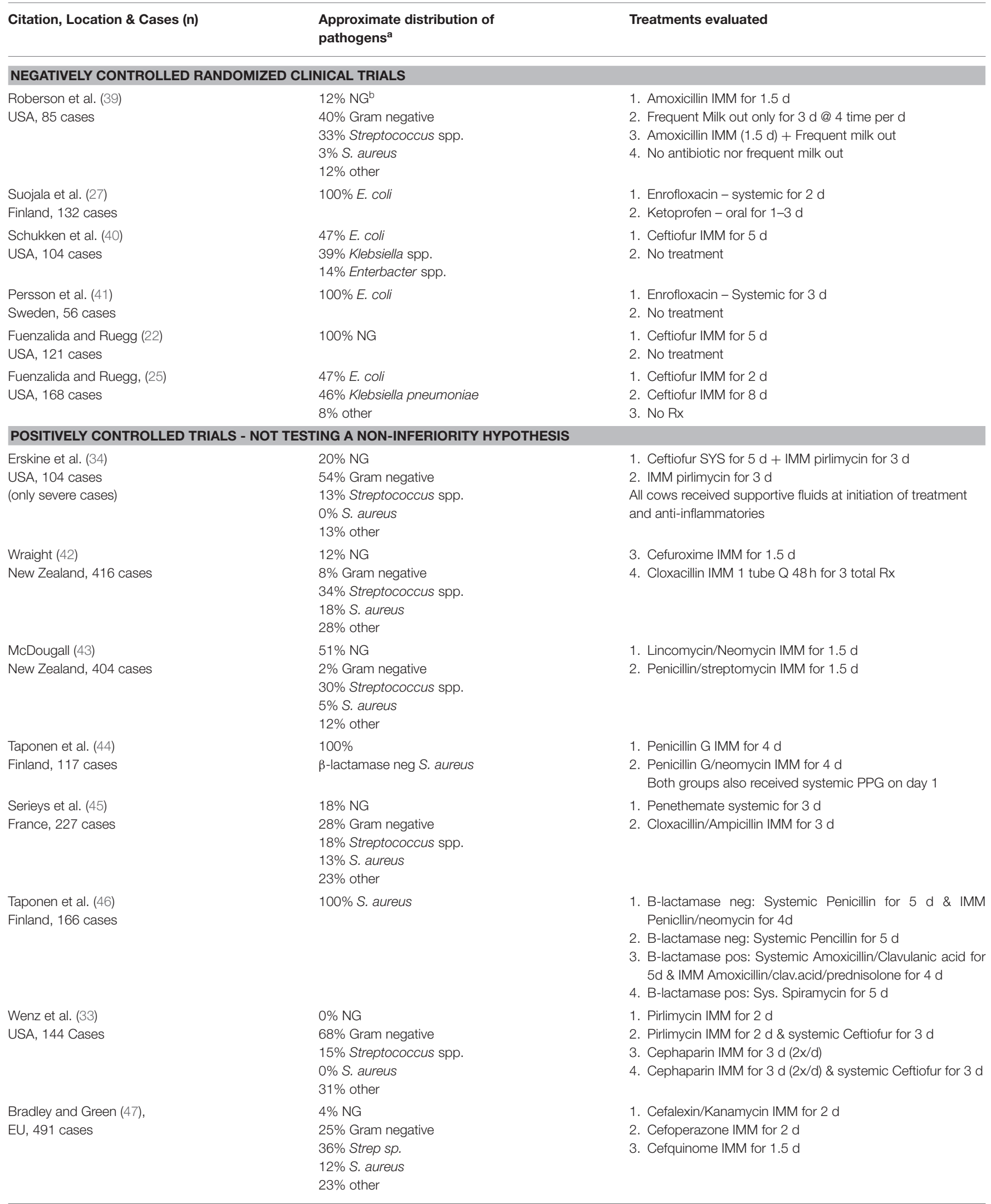


TABLE 1 | Continued

\begin{tabular}{|c|c|c|}
\hline Citation, Location \& Cases (n) & $\begin{array}{l}\text { Approximate distribution of } \\
\text { pathogens }^{a}\end{array}$ & Treatments evaluated \\
\hline $\begin{array}{l}\text { Swinkels et al. (48) EU, } \\
206 \text { cases }\end{array}$ & $100 \%$ S. aureus & $\begin{array}{l}\text { 1. Cefquinome IMM for } 1.5 d \\
\text { 2. Cefquinome IMM for } 5 d\end{array}$ \\
\hline $\begin{array}{l}\text { Kalmus et al. (49) } \\
\text { Estonia, } 140 \text { cases }\end{array}$ & $\begin{array}{l}\text { 0\% NG } \\
\text { 0\% Gram negative } \\
71 \% \text { Streptococcus spp. } \\
6 \% \text { S. aureus } \\
23 \% \text { other }\end{array}$ & $\begin{array}{l}\text { 1. BenzyIPenicillin systemic for } 5 d \\
\text { 2. BenzyIPenicillin IMM for } 5 d\end{array}$ \\
\hline $\begin{array}{l}\text { Truchetti et al. (50) } \\
\text { Canada, } 241 \text { cases }\end{array}$ & $\begin{array}{l}32 \% \text { NG } \\
9 \% \text { Gram negative } \\
20 \% \text { Streptococcus spp. } \\
26 \% \text { S. aureus } \\
13 \% \text { other }\end{array}$ & $\begin{array}{l}\text { 1. Ceftiofur IMM for } 2 d \\
\text { 2. Ceftiofur IMM for } 5 d\end{array}$ \\
\hline $\begin{array}{l}\text { Cortinhas et al. (51) } \\
\text { Brazil, } 264 \text { cases }\end{array}$ & $\begin{array}{l}50 \% \text { NG } \\
10 \% \text { Gram negative } \\
22 \% \text { Streptococcus spp. } \\
8 \% \text { S. aureus } \\
10 \% \text { other }\end{array}$ & $\begin{array}{l}\text { 1. Ceftiofur } I M M \text { for } 4 d \text { (moderate cases also received } \\
\text { prednisolone) } \\
\text { 2. Tetracycline/neomycin/bacitracin/prednisolone } I M M \text { for } 4 d\end{array}$ \\
\hline $\begin{array}{l}\text { Viveros et al. (52) } \\
\text { Mexico, } 292 \text { cases }\end{array}$ & $\begin{array}{l}38 \% \text { NG } \\
18 \% \text { Gram negative } \\
\text { 13\% Streptococcus spp. } \\
9 \% \text { S. aureus } \\
22 \% \text { other }\end{array}$ & $\begin{array}{l}\text { 1. Enrofloxacin suspension IMM for } 3 d \\
\text { 2. Enrofloxacin powder IMM for } 3 d \\
\text { 3. Ceftiofur IMM for } 3 d \\
\text { 4. Enrofloxacin systemic for } 3 d\end{array}$ \\
\hline $\begin{array}{l}\text { McDougall et al. (53) } \\
\text { New Zealand, } 304 \text { cases }\end{array}$ & $\begin{array}{l}23 \% \text { NG } \\
4 \% \text { Gram negative } \\
55 \% \text { Streptococcus spp. } \\
5 \% \text { S. aureus } \\
13 \% \text { other }\end{array}$ & $\begin{array}{l}\text { 1. Amoxicillin/clavulanic acid IMM for } 1.5 \mathrm{~d} \\
\text { 2. Amoxicillin/clavulanic acid IMM for } 2.5 \mathrm{~d}\end{array}$ \\
\hline
\end{tabular}

\section{POSITIVELY CONTROLLED TRIALS - TESTING A NON-INFERIORITY OR "EQUIVALENCY" HYPOTHESIS}

McDougall et al. (54)

$\mathrm{NZ}, 1,561$ cases

McDougall et al. (21)

New Zealand, 662 cases

Schukken et al. (55)

USA, 296 cases

Vasquez et al. (56)

USA, 588 cases

Bryan et al. (57)

New Zealand, 458 Cases

Tomazi et al. (58)

Brazil, 346 cases
$23 \% N G$

$1 \%$ Gram negative

38\% Streptococcus spp.

$17 \%$ S. aureus

$18 \%$ other

$0 \% N G$

$0 \%$ Gram negative

79\% Streptococcus spp.

$6 \%$ S. aureus

$15 \%$ other

$28 \% N G$

$25 \%$ Gram -

1. Penicillin $\mathrm{G} I M M$ for $1-1.5 d$

2. Cefuroxime IMM for 1-1.5 d

3. Pencillin/streptomycin IMM for 1-1.5 d

1. Penethemate systemic for $3 d$

2. Tylosin systemic for $3 d$

1. Cephaparin IMM for $1 \mathrm{~d}$

$23 \%$ Streptococcus spp.

$3 \%$ S. aureus

$21 \%$ other

$36 \%$ NG

22\% Gram negative

$22 \%$ Streptococcus spp.

$8 \%$ S. aureus

$12 \%$ other

\section{$0 \% \mathrm{NG}$}

$3 \%$ Gram negative

$58 \%$ Streptococcus spp.

$27 \%$ S. aureus

$12 \%$ other

$30 \% N G$

$12 \%$ Gram negative

$18 \%$ Streptococcus spp.

$10 \%$ S. aureus

$30 \%$ other
2. Ceftiofur IMM for $5 \mathrm{~d}$

1. Ceftiofur IMM for $5 d$

2. Hetacillin IMM for $3 d$

1. Penicillin/cloxacillin IMM for $3 \mathrm{~d}$

2. Tetracycline/oleandromycin/neomysin/prednisolone IMM for $3 d$

1. Cephaparin/prednisolone IMM for $2 \mathrm{~d}$

2. Tetracycline/neomycin/bacitracin/prednisolone IMM for $2 \mathrm{~d}$

${ }^{a}$ Overall enrollment estimated from overall etiologies reported in results, subsets of data were often used to calculate various outcomes; ${ }^{b}$ No growth on culture. 


\section{Study Designs Included in This Review}

Mastitis efficacy trials are challenging to perform and use different study designs. Some trials are performed using experimental challenge where cows are purposefully infected using a well-described bacterial strain $(61,62)$. Experimental challenge studies are useful for answering narrow research questions, but natural exposure trials are preferred for evaluating treatments and no challenge studies were included. Natural exposure trials randomly allocate cows to treatments and compare outcomes to either a non-treated control group or a positive control group. Non-treated ("negatively-controlled") control groups are considered the gold standard for determining efficacy and are able to determine if treatments improve ("are superior to") outcomes as compared to non-treated cows (or cows treated with a placebo). The null hypothesis in a superiority trial states that treatments are equally effective while the alternative hypothesis states that they differ. The inclusion of non-treated animals allows the determination of spontaneous cure so the additional benefit of treatment can be determined. Welfare concerns about not treating cows affected with mastitis have limited the number of negatively controlled trials that have been performed and only 6 of the 26 trials included in this review were negatively controlled. Only one of the negatively controlled studies included Gram-positive pathogens (39).

Positively controlled clinical trials are frequently used to assess mastitis treatments (Table 1) and can be designed to demonstrate superiority or non-inferiority. Of positively-controlled studies included in this review $(n=20), 6$ were specifically designed to test non-inferiority, 1 stated that they were testing a superiority hypothesis, while the remainder $(n=13)$ compared outcomes among treatments but did not define the type of hypothesis that they were testing. The lack of a non-treated control group makes it impossible to separate treatment effects from spontaneous cures and superiority is rarely demonstrated. The null hypothesis in a non-inferiority trial states that the treatments differ while the alternative hypothesis states that they are non-inferior. Non-inferiority studies, include a pre-defined margin of noninferiority for each outcome (usually 15\%) and conclude that the new treatment is superior, non-inferior, inconclusive or inferior to the comparison treatment $(55,63)$. It is important to recognize that the inclusion of culture-negative cases in trials will skew the results toward positive outcomes (regardless of treatment) as the majority of these cases have achieved spontaneous bacteriological cure at the time of detection $(22,23)$. Mathematical realities dictate that inclusion of a large proportion of culture-negative and non-severe Gram-negative cases in non-inferiority trials will almost always result in a finding of non-inferior unless the "trueefficacy" of one of the products is very low. Of 6 non-interiority trials included in this review, 4 enrolled cases regardless of etiology (including culture-negative) and all 6 concluded that the "new treatment" was non-inferior (or inconclusive) to the comparator product. All of the non-inferiority trails included in this review evaluated commercially available products which infers that the drug approval process resulted in an acceptable level of efficacy for at least some outcomes. Outcomes of noninferiority trials should always be evaluated relative to the distribution of pathogens enrolled in the study with emphasis on the number of enrolled cases that would likely be within the spectrum of activity of the products being compared.

\section{OUTCOMES EVALUATED TO DETERMINE EFFICACY}

Clinical trials can include both microbiological and clinical outcomes but other than bacteriological cure (BC), there is little consistency in outcomes that are reported (Table 2). In the studies included in this review, BC was reported by 23 of 26 studies. Other outcomes include new intramammary infections (NIMI) (reported in 6 studies), clinical cure (24 studies), recurrence of another clinical case (4 studies), posttreatment SCC (14 studies), post-treatment milk yield (6 studies), culling (8 studies), and miscellaneous other outcomes (such as measures of inflammation or variations of BC). Publication bias does not seem to have influenced these trials as only half of the studies reported a significant difference among treatment groups for at least 1 outcome.

\section{Bacteriological Cure and New Intramammary Infection}

The purpose of antibiotic treatment is to enhance clearance of bacterial pathogens and treatment efficacy is initially evaluated based on estimates of BC. This outcome is very relevant for approving new products but is rarely evaluated in a clinical setting. Bacteriological cure is assessed by comparison of recovery of bacteria from milk samples collected when the case is detected to recovery of the same isolate from milk samples collected at various intervals after treatment is completed. Sampling strategies and intervals used to define BC vary among studies (Table 3). Some researchers defined BC based on results of a single post-treatment milk sample, while other studies require the absence of the causative pathogen in multiple samples (usually collected at 7-d intervals). In the included studies, apparent BC ranged from about $27-95 \%$, but it is important to recognize that comparisons among studies are not accurate due to differences in the distribution of pathogens and sampling periods. The overall means and ranges of BC were 69\% (27-95\%; $n=35), 68 \%(33-$ $91 \% ; n=13)$ and $60 \%(38-87 \% ; n=6)$ for all IMM antimicrobial therapies, systemic or systemic and IMM therapies combined or no antimicrobial treatment, respectively.

Bacteriological cures result from the combined effect of the host immune response (spontaneous cure) and the effect of treatment (treatment cure) and the value of antimicrobial therapy is greatest for pathogens that have a low rate of spontaneous cure and high rate of treatment cure (such as IMI caused by $S$. agalactiae). Among mastitis pathogens, expected rates of spontaneous bacteriological cure vary widely. The greatest contrast is between expectations of spontaneous bacteriological cure of IMI caused by S. aureus (close to zero) and Escherichia coli (about 90\%) $(25,26)$. Limited efficacy of antibiotic therapy is well-documented for IMI caused by $S$. aureus $(38,64)$ and some pathogens lack targets for antimicrobial therapy (e.g., yeast, Prototheca bovis, Mycoplasma spp. and others) and are considered to be intrinsically resistant to all approved 
TABLE 2 | Outcomes evaluated in 26 clinical mastitis treatment trials.

\begin{tabular}{|c|c|c|c|c|c|c|c|}
\hline Study & Bact. cure & New IMI & Clinical cure & scc & Recurrence & Milk yield & Culling \\
\hline \multicolumn{8}{|c|}{ NEGATIVELY CONTROLLED RANDOMIZED CLINICAL TRIALS } \\
\hline Roberson et al. (39) & $N S D^{a}$ & NSD & NSD & SIG & Defined as CC NSD & SIG & \\
\hline Suojala et al. (27) & NSD & & NSD at day 21 & No stats & & & NSD \\
\hline Schukken et al. (40) & SIG & & SIG & NSD & & NSD & SIG \\
\hline Persson et al. (41) & & & & SIG & & & \\
\hline \multicolumn{8}{|c|}{ POSITIVELY CONTROLLED TRIALS - NOT TESTING A NON-INFERIORITY HYPOTHESIS } \\
\hline Erskine et al. (34) & & & NSD & & & & \\
\hline Wraight (42) & NSD & & NSD & & & & \\
\hline McDougall (43) & NSD & & SIG & NSD & SIG & NSD & \\
\hline Taponen et al. (44) & NSD & & NSD & & & & \\
\hline Bradley and Green (47) & NSD & NSD & & & & & \\
\hline Swinkels et al. (48) & NSD & NSD & SIG & NSD & & & \\
\hline Kalmus et al. (49) & NSD & & NSD & NSD & & & NSD \\
\hline Truchetti et al. (50) & SIG & NSD & NSD & & & & \\
\hline Cortinhas et al. (51) & NSD & NSD & NSD & & & & \\
\hline Viveros et al. (52) & NSD & & SIG & SIG & & & \\
\hline McDougall et al. (53) & NSD & & SIG & NSD & & & \\
\hline \multicolumn{8}{|c|}{ POSITIVELY CONTROLLED TRIALS - TESTING A NON-INFERIORITY OR "EQUIVALENCY" HYPOTHESIS } \\
\hline McDougall et al. (54) & NSD & & SIG & & Defined as CC & & \\
\hline McDougall et al. (21) & NSD & & SIG & NSD & Defined as CC & NSD & NSD \\
\hline Schukken et al. (55) & $\mathrm{NI}^{\mathrm{C}}$ & & NSD & & & & $\mathrm{NI}$ \\
\hline
\end{tabular}

${ }^{a}$ No significant difference; ${ }^{b}$ statistically significant difference among treatments; ${ }^{c}$ non-inferior.

antimicrobials. It is important to reiterate, that even with highly efficacious drugs the benefit of antimicrobial therapy is only for the cases that do not achieve spontaneous bacteriological cure; thus, the marginal value of antibiotic therapy decreases for cases caused by E. coli or other pathogens with high rates of spontaneous cure.

Among the 23 trials that evaluated bacteriological cure, statistically significant differences among treatments were observed in only 4 trials while 16 reported no significant differences and 3 trials concluded the evaluated treatments were non-inferior (Table 3). Two of the trials that reported significant differences in $\mathrm{BC}$ enrolled only Gram-negative cases and compared IMM antimicrobial treatment to non-treated controls $(25,40)$. The distribution of pathogens in both studies included a considerable proportion of Klebsiella spp. which influenced overall BC of the combined groups. Fuenzalida and Ruegg (25) identified an interaction of pathogen by treatment group and reported BC of 18\% (non-treated K. pneumoniae), 74\% (treated K. pneumoniae), 97\% (non-treated E. coli) and 99\% (treated E. coli). Schukken et al. (40) reported significant differences in BC for cases caused by both E. coli and Klebsiella spp. but this study is unique in reporting exceptionally low spontaneous cure rates of $E$. coli cases, which the authors attributed to persistent infections. In spite of finding significant differences in BC, neither of these studies reported biologically important differences in important clinical outcomes. Taponen et al. (46) reported BC of clinical mastitis caused by $S$. aureus that were either $\beta$-lactamase negative or positive and were treated with either systemic penicillin \& an IMM combination product containing penicillin \& neomycin or received systemic penicillin alone. While a significant difference was identified among treatments, BC was dramatically decreased for $\beta$-lactamase positive organisms. Truchetti et al. (50) compared shorter (2d) vs. longer (5d) therapy using IMM ceftiofur and reported a significant difference in BC but no differences in any clinical outcomes. Over $30 \%$ of cases enrolled in this study were culturenegative and $26 \%$ were caused by $S$. aureus thus the impact of $3 \mathrm{~d}$ difference in therapy was likely biologically irrelevant. In general, no clear relationship between BC and important clinical outcomes (such as new IMI, clinical cure, recurrence, SCC, milk 
TABLE 3 | Bacteriological cure (BC) definitions and outcomes for 24 studies reporting this outcome.

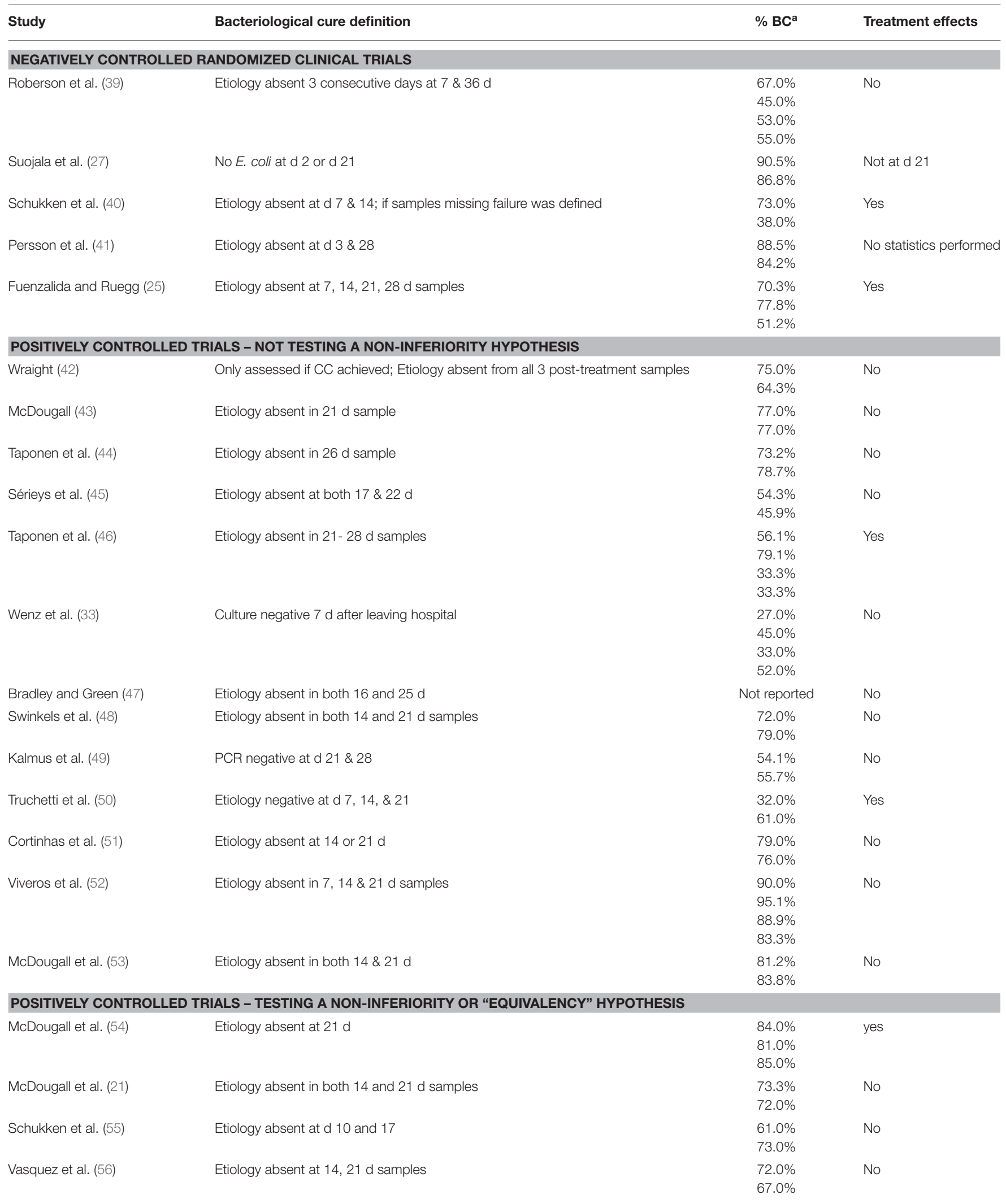


TABLE 3 | Continued

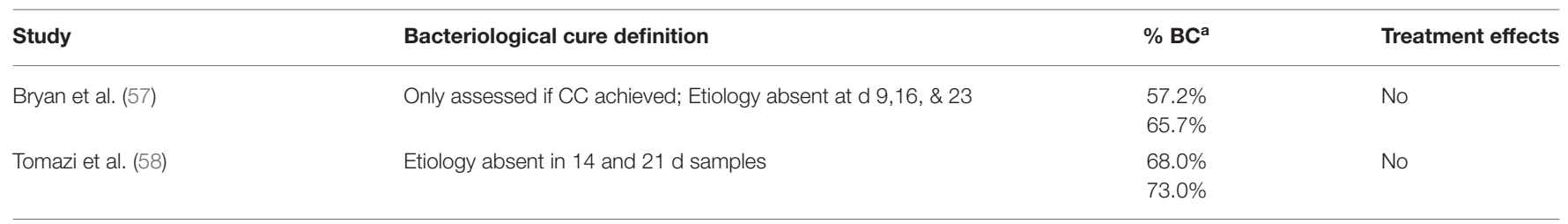

a Proportion of BC are listed in same order of treatments defined in Table 1.

TABLE 4 | Statistical significance of other study outcomes categorized by significance of bacteriological cure in 23 clinical trials that evaluated bacteriological cure.

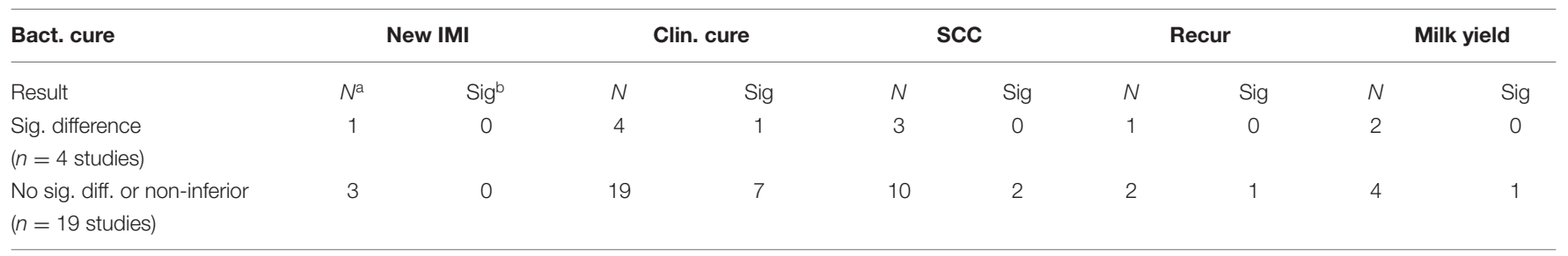

${ }^{a}$ Number of studies evaluating the outcome; ${ }^{b}$ number of studies reporting significant difference among treatment groups in that outcome.

yield or culling) were apparent (Table 4). Thus, while achieving $\mathrm{BC}$ is the goal of antimicrobial therapy, the finding of differences in $\mathrm{BC}$ in research trials does not appear to be predictive of differences in clinical outcomes.

New Intramammary infections are typically defined based on recovery of a different pathogen in follow-up milk samples but in the study that enrolled culture negative cases (22), NIMI was defined as recovery of any pathogen in the 14 and $21 \mathrm{~d}$ followup samples. While this outcome was not significant in any trials, recovery of both the etiological agent and new pathogens from follow-up samples after treatment is usually greater at earlier sampling periods $(22,25)$ as compared to samples collected after $14 \mathrm{~d}$ and in some instances may reflect differences among pathogens in duration of time to achieve both spontaneous and treatment clearance.

\section{CLINICAL OUTCOMES}

\section{Clinical Cure (CC)}

Almost all studies ( $n=24$; Table 5) evaluated "clinical cure" but the definition of this outcome varies enormously. Most researchers $(67 \%)$ defined CC based on observations that the milk and/or the mammary gland returned to normal appearance, but the day of observation varied from 2 to 28 days after treatment and some relied on single observations, while other researchers required multiple observations. Of studies that defined CC based on observation of clinical signs, the proportion achieving CC was least $(\mathrm{CC}<15 \%)$ for studies that performed observations very early and evaluated systemic therapies $(27,41)$. For CC estimated based on visual observations after day 3, values of CC ranged from $25 \%$ to $98 \%$ with a median value of $81 \%$. Other definitions of CC included retreatment within a defined time period (4 studies), use of scoring systems (2 studies) or a combination of methods (2 studies). Of 7 studies that reported significant differences in CC among treatments, 4 defined CC based on retreatment, 2 used comparison of defined scoring systems and 1 evaluated CC within 4 days of treatment. While achieving CC is the practical goal on farms, this outcome is not useful to determine effectiveness of antimicrobial therapy. In most cases of clinical mastitis, inflammation is self-limiting and regardless of $\mathrm{BC}$, and for the majority of cases, milk will return to normal appearance by day 7 (30). There is almost no evidence that selection of an antimicrobial has a significant impact on this outcome and CC should not be used to make decisions about treatment efficacy.

\section{Post-treatment SCC}

Similar to CC, a variety of definitions and sampling periods were used to assess SCC responses in the 14 studies that included this outcome (Table 6). Seven studies each assessed SCC at the quarter or composite level and dilution of healthy milk from unaffected quarters likely influenced results of studies that used composite milk samples. Sampling periods ranged from 7 to 90 days after treatment, and all studies that assessed SCC at multiple periods reported a gradual decline in SCC as time passed. While some researchers compared linear scores, other researchers compared the proportion of samples that were defined as "healthy" based on a threshold or either 200,000 or 250,000 cells/mL. Of the 14 studies that included this outcome, only 3 reported significant differences in their measure of SCC. One researcher used the California Mastitis Test on quarter milk samples collected at day 36 posttreatment and reported significantly fewer quarters below "trace score" for quarters that did not receive IMM treatment but received frequent milking (39). Interestingly, no difference was seen in non-treated control quarters that were not frequently milked. In another study, fewer quarters that received IMM antibiotics (as compared to systemic) achieved SCC $<250,000$ cells/mL by 22 days post-treatment (45) and a $3 \mathrm{rd}$ study reported significantly lower SCC at days 7 and 14 but those effects were not significant by day 22 (52). When assessing 
TABLE 5 | Clinical cure definition and outcomes for 24 studies reporting this outcome.

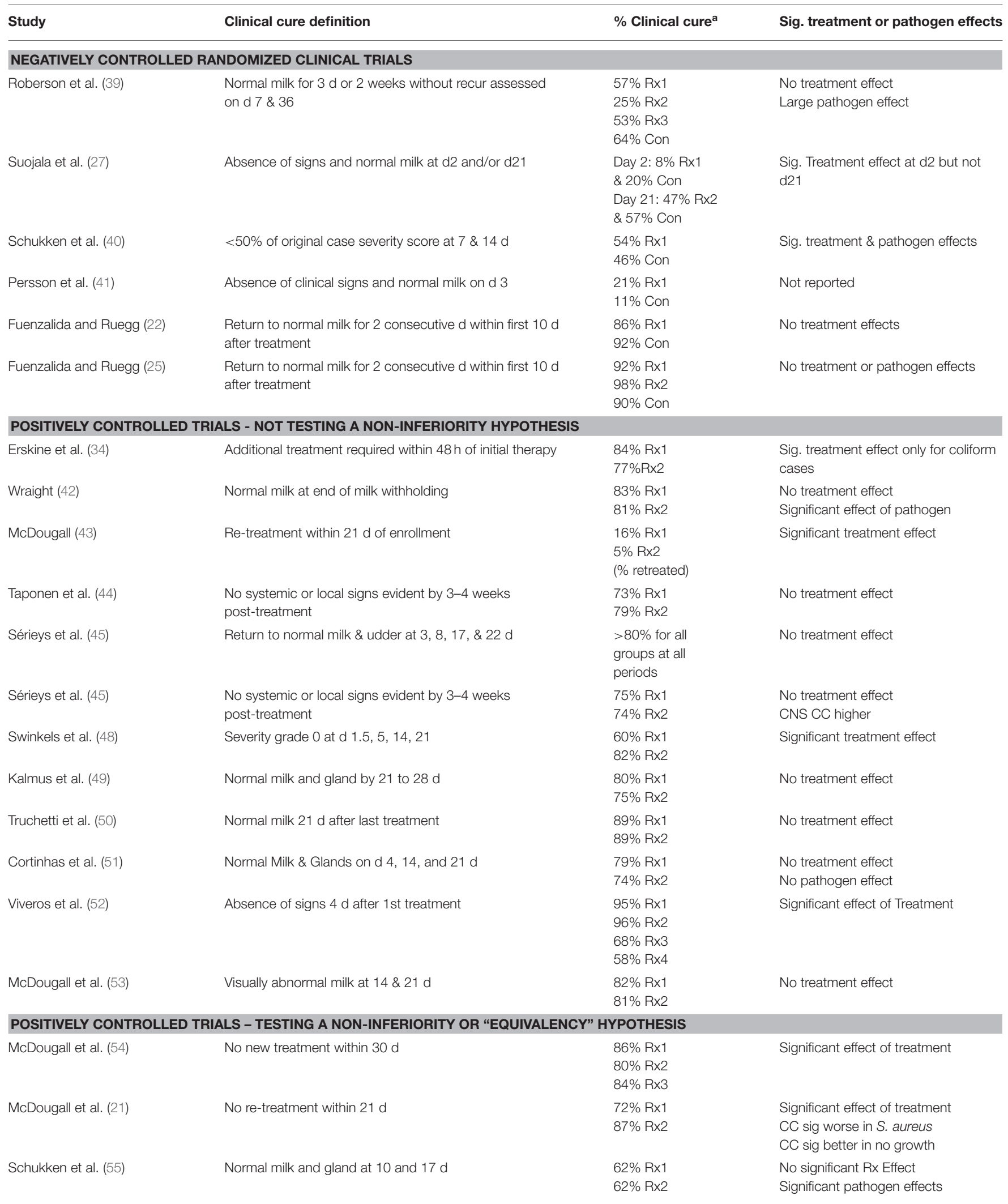


TABLE 5 | Continued

\begin{tabular}{|c|c|c|c|}
\hline Study & Clinical cure definition & $\%$ Clinical cure ${ }^{a}$ & Sig. treatment or pathogen effects \\
\hline Vasquez et al. (56) & Normal milk and udder 2 to $5 \mathrm{~d}$ & $\begin{array}{l}64 \% R \times 1 \\
68 \% R \times 2\end{array}$ & No Treatment effect \\
\hline Tomazi et al. (58) & Milk and gland normal $48 \mathrm{~h}$ after last treatment & $\begin{array}{l}88 \% R \times 1 \\
94 \% R \times 2\end{array}$ & $\begin{array}{l}\text { No } \\
\text { No }\end{array}$ \\
\hline
\end{tabular}

a Proportions of clinical cure are listed in same order of treatments defined in Table 1.

TABLE 6 | SCC definitions and outcomes for 14 studies reporting this outcome.

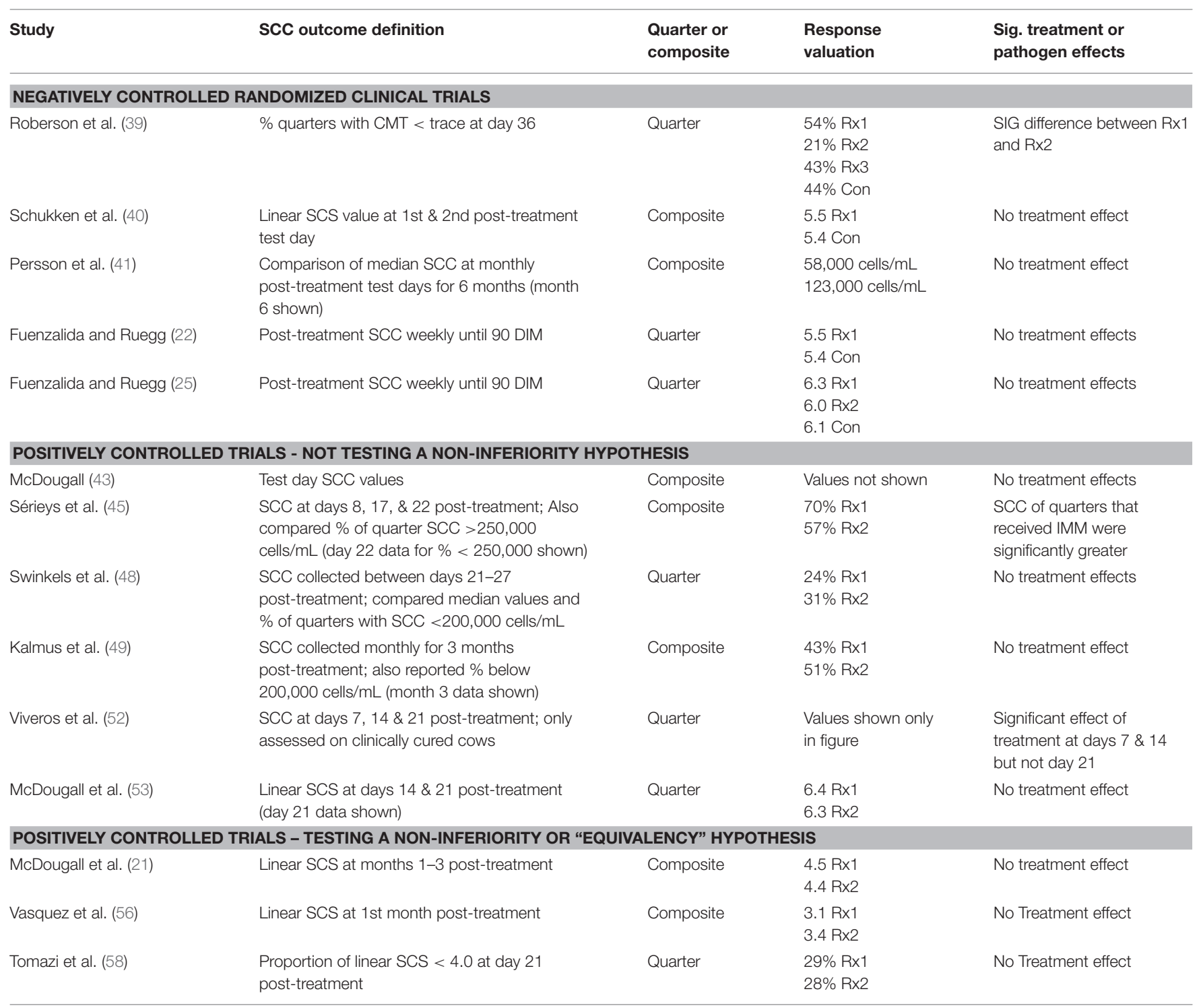

SCC responses, it is important to recognize that quarter-level measurements will more accurately reflect ongoing inflammation that may indicate persistent IMI. When BC is achieved SCC will gradually decline and the speed of return to a "healthy" level is influenced by etiology. Assessment of SCC responses should be performed at the quarter level and should continue for at least 21 days. Somatic cell count responses are a practical outcome that can be used as an indicator of treatment success on farms, but a gradual (rather than immediate) decline should be expected. When using composite milk samples, a lower threshold 
$(<150,000$ cells/mL) may help prevent misclassification of ongoing subclinical infections that can result after failure to cure clinical cases.

\section{Recurrence, Milk Yield, and Retention Within the Herd}

A few studies have evaluated other important clinical outcomes. Only 4 studies reported recurrence as a distinct outcome (22, $25,33,43)$ but several included recurrence in their definition of clinical cure (or "clinical failure") $(53,54)$. Like other outcomes, recurrence can be defined at either the quarter or cow level, but when used to assess treatment this outcome should always be assessed relative to the affected quarter. Recurrence ranged from about $5-30 \%$ and was strongly influenced by additional risk factors such as parity (older cows are at greater risk of recurrence), etiology (culture positive are at greater risk as compared to culture negative), and increased milk yield. While two studies reported significant differences in recurrence based on treatment, this outcome is influenced by many other factors and should be interpreted cautiously. Post-treatment milk yield is an obviously important outcome that requires a prolonged follow-up period and has been evaluated infrequently in mastitis trials $(22,25,39,40,43,54)$. Of the 6 studies evaluating this outcome, 4 included a non-treated control group and the only significant finding was one study that reported non-treated control animals had the greatest post-treatment milk yield (39). Similarly, a significant difference in retention (or culling) after treatment was reported in only 1 of 8 studies that evaluated this outcome $(22,25,27,33,40,49,55,65)$. Culling is a very difficult outcome to assess as it is influenced by many factors including non-blinded studies that allow farmers to remove cows without a withholding period if they have not received antimicrobial therapy. While all of these outcomes are relevant and useful for dairy farmers, there is insufficient evidence to suggest that they are influenced by choices made about mastitis treatment.

\section{REFERENCES}

1. USDA. Dairy 2014. In: Health and Management Practices on U.S. Dairy Operations, 2014. Fort Collins, CO: USDA-APHIS-VS-CEAH-NAHMS (2018).

2. Leite de Campos J, Steinberger A, Goldberg TS, Safdar N, Kates A, Shutske J, et al. Frequency of antimicrobial usage on treatment for bacterial diseases occurring in cows on large dairy farms. J Dairy Sci. (2019) 101(Supp. 2):135.

3. Olde Riekerink RGM, Barkema HW, Kelton DF, Scholl DT. Incidence rate of clinical mastitis on canadian dairy farms. J Dairy Sci. (2008) 91:136677. doi: 10.3168/jds.2007-0757

4. Sordillo LM, Shafer-Weaver K, DeRosa D. Immunobiology of the mammary gland. J Dairy Sci. (1997) 80:1851-65. doi: 10.3168/jds.S0022-0302(97) 76121-6

5. Ruegg PL. A 100-Year review: mastitis detection, management, and prevention. J Dairy Sci. (2017) 100:10381-97. doi: 10.3168/jds.2017-13023

6. Swinkels JM, Rooijendijk JG, Zadoks RN, Hogeveen H. Use of partial budgeting to determine the economic benefits of antibiotic treatment of chronic subclinical mastitis caused by Streptococcus uberis or Streptococcus dysgalactiae. J Dairy Res. (2005) 72:75-85. doi: 10.1017/S00220299040 00603

\section{CONCLUSIONS AND CLINICAL IMPLICATIONS}

Over the last 20 years, very few mastitis trials have been conducted to differentiate among mastitis treatment protocols and the inclusion of multiple etiologies and culture negative cases in efficacy studies have resulted in little ability to differentiate among treatments. Few studies have been conducted that evaluated antimicrobial therapies approved to treat clinical mastitis in N. America. With rare exceptions, researchers have not reported significant differences in most microbiological or clinical outcomes and non-inferiority trials have not concluded that there are differences among products. There is noevidence that IMM products approved for treatment of clinical mastitis caused by Gram-positive organisms vary in efficacy and other characteristics of approved products (dosing interval, withholding period, price etc.) can be used to make treatment decisions. When possible, etiology should be determined before treatment, the probability of spontaneous cure should be considered and the spectrum of antimicrobial activity of the approved product should be appropriate for the etiological agent. Research has demonstrated that cases of mastitis that are culturenegative at detection or are caused by $E$. coli rarely benefit from antimicrobial therapy and use of antimicrobials to treat these cases should be considered on an individual case basis. Associations between $\mathrm{BC}$ and clinical outcomes are very weak, and resolution of inflammation (duration of abnormal milk) is not a reliable indicator of therapeutic efficacy. Among potential indicators that can be used clinically, evaluation of continued decline in quarter-level SCC appears to be the most reliable indicator of success.

\section{AUTHOR CONTRIBUTIONS}

The author confirms being the sole contributor of this work and has approved it for publication.

7. Steeneveld W, Swinkels J, Hogeveen H. Stochastic modelling to assess economic effects of treatment of chronic subclinical mastitis caused by Streptococcus uberis. J Dairy Res. (2007) 74:459-67. doi: 10.1017/S0022029907002828

8. USDA. Dairy 2014. In: Milk Quality, Milking Procedures, and Mastitis in the United States, 2014. Fort Collins, CO: USDA-APHIS-VS-CEAH-NAHMS. (2016).

9. Levison LJ, Miller-Chuson EK, Tucker AL, Bergeron R, Leslie KE, Barkema $\mathrm{H}$, et al. Incidence rate of pathogen-specific clinical mastitis on conventiaonl and organic Canadian dairy farms. J Dairy Sci. (2016) 99:134150. doi: 10.3168/jds.2015-9809

10. Verbeke J, Piepers S, Supré K, De Vliegher S. Pathogen-specific incidence rate of clinical mastitis in Flemish dairy herds, severity, and association with herd hygiene. J Dairy Sci. (2014) 97:6926-34. doi: 10.3168/jds.2014-8173

11. Kossaibati MA, Hovi M, Esslemont RJ. Incidence of clinical mastitis in dairy herds in England. Vet Rec. (1998) 143:649-53. doi: 10.1136/vr.143.24.649

12. Gao J, Barkema HW, Zhang L, Liu G, Deng Z, Cai L, et al. Incidence of clinical mastitis and distribution of pathogens on large Chinese dairy farms. J Dairy Sci. (2017) 100:4797-806. doi: 10.3168/jds.2016-12334

13. Wenz JR, Barrington GM, Garry FB, Dinsmore RP, Callan RJ. Use of systemic disease signs to assess disease severity in dairy cows 
with acute coliform mastitis. J Am Vet Med Assoc. (2001) 218:56772. doi: 10.2460/javma.2001.218.567

14. Ruegg PL. Making antibiotic treatment decisions for clinical mastitis. Vet Clin North Am Food Anim Pract. (2018) 34:413-25. doi: 10.1016/j.cvfa.2018.06.002

15. Lago A, Godden SM, Bey R, Ruegg PL, Leslie K. The selective treatment of clinical mastitis based on on-farm culture results: I. Effects on antibiotic use, milk withholding time, and short-term clinical and bacteriological outcomes. J Dairy Sci. (2011) 94:4441-56. doi: 10.3168/jds.2010-4046

16. Vasquez AK, Nydam DV, Capel MB, Eicker S, Virkler PD. Clinical outcome comparison of immediate blanket treatment versus a delayed pathogen-based treatment protocol for clinical mastitis in a New York dairy herd. J Dairy Sci. (2017) 100:2992-3003. doi: 10.3168/jds.2016-11614

17. Valeeva NI, Lam TJGM, Hogeveen H. Motivation of dairy farmers to improve mastitis management. J Dairy Sci. (2007) 90:4466-77. doi: 10.3168/jds.2007-0095

18. Oliveira L, Hulland C, Ruegg PL. Characterization of clinical mastitis occurring in cows on 50 large dairy herds in Wisconsin. J Dairy Sci. (2013) 96:7538-49. doi: 10.3168/jds.2012-6078

19. Ruegg PL. Understanding the economic impact of mastitis. The role of duration and drug selection. In: Third Am Assoc Bov Pract Annual Recent Graduate Conference. Columbus OH: Am. Assoc Bov Prac. (2020). p. 84-91.

20. Bradley AJ, Leach KA, Breen JE, Green LE, Green MJ. Survey of the incidence and aetiology of mastitis on dairy farms in England and Wales. Vet Rec. (2007) 160:253-7. doi: 10.1136/vr.160.8.253

21. McDougall S, Agnew KE, Cursons R, Hou XX, Compton CR. Parenteral treatment of clinical mastitis with tylosin base or penethamate hydriodide in dairy cattle. J Dairy Sci. (2007) 90:779-89. doi: 10.3168/jds.S0022-0302(07)71562-X

22. Fuenzalida MJ, Ruegg PL. Negatively controlled, randomized clinical trial to evaluate use of intramammary ceftiofur for treatment of nonsevere culture-negative clinical mastitis. J Dairy Sci. (2019) 102:3321-38. doi: 10.3168/jds.2018-15497

23. Latosinski GS, Amzalak MJ, Pantoja JCF. Efficacy of ketoprofen for treatment of spontaneous, culture-negative, mild cases of clinical mastitis: a randomized, controlled superiority trial. J Dairy Sci. (2020) 103:262435. doi: $10.3168 /$ jds.2019-17504

24. Lago A, Godden SM, Bey R, Ruegg PL, Leslie K. The selective treatment of clinical mastitis based on on-farm culture results: II. Effects on lactation performance, including clinical mastitis recurrence, somatic cell count, milk production, and cow survival. J Dairy Sci. (2011) 94:445767. doi: $10.3168 /$ jds.2010-4047

25. Fuenzalida MJ, Ruegg PL. Negatively controlled, randomized clinical trial to evaluate intramammary treatment of nonsevere, gram-negative clinical mastitis. J Dairy Sci. (2019) 102:5438-57. doi: 10.3168/jds.2018-16156

26. Suojala L, Kaartinen L, Pyorala S. Treatment for bovine Escherichia coli mastitis - an evidence-based approach. J Vet Pharmacol Ther. (2013) 36:52131. doi: 10.1111/jvp.12057

27. Suojala L, Simojoki H, Mustonen K, Kaartinen L, Pyorala S. Efficacy of enrofloxacin in the treatment of naturally occurring acute clinical Escherichia coli mastitis. J Dairy Sci. (2010) 93:1960-9. doi: 10.3168/jds. 2009-2462

28. Pinzon-Sanchez C, Cabrera VE, Ruegg PL. Decision tree analysis of treatment strategies for mild and moderate cases of clinical mastitis occurring in early lactation. J Dairy Sci. (2011) 94:1873-92. doi: 10.3168/jds. 2010-3930

29. Down PM, Bradley AJ, Breen JE, Green MJ. Factors affecting the cost-effectiveness of on-farm culture prior to the treatment of clinical mastitis in dairy cows. Prev Vet Med. (2017) 145:919. doi: 10.1016/j.prevetmed.2017.07.006

30. Pinzon-Sanchez C, Ruegg PL. Risk factors associated with short-term post-treatment outcomes of clinical mastitis. J Dairy Sci. (2011) 94:3397410. doi: $10.3168 /$ jds.2010-3925

31. Wagner S, Erskine R. Antimicrobial drug use in mastitis. In: Giguere S, Prescott JF, Dowling PM, editors. Antimicrobial Therapy in Veterinary Medicine. 5th ed. Ames IA: Wiley Blackwell (2013). p. 519-28. doi: 10.1002/9781118675014.ch30

32. Boerlin P, White DG. Antimicrobial resistance and its epidemiology. In: Giguere S, Prescott JF, Dowling PM, editors. Antimicrobial Therapy in
Veterinary Medicine. 5th ed. Ames, IA: Wiley Blackwell (2013). p. 2140. doi: 10.1002/9781118675014.ch3

33. Wenz JR, Garry FB, Lombard JE, Eilia R, Prentice D, Dinsmore RP. Efficacy of parenteral ceftiofur for treatment of systemically mild clinical mastitis in dairy cattle. J Dairy Sci. (2005) 88:3496-9. doi: 10.3168/jds.S0022-0302(05)73034-4

34. Erskine RJ, Bartlett PC, VanLente JL, Phipps CR. Efficacy of systemic ceftiofur as a therapy for severe clinical mastitis in dairy cattle. J Dairy Sci. (2002) 85:2571-5. doi: 10.3168/jds.S0022-0302(02)74340-3

35. Oliver SP, Murinda SE, Jayarao BM. Impact of antibiotic use in adult dairy cows on antimicrobial resistance of veterinary and human pathogens: a comprehensive review. Foodborne Pathog Dis. (2011) 8:33755. doi: $10.1089 /$ fpd.2010.0730

36. Burvenich C, Van Merris V, Mehrzad J, Diez-Fraile A, Duchateau L. Severity of E. coli mastitis is mainly determined by cow factors. Vet Res. (2003) 34:521-64. doi: 10.1051/vetres:2003023

37. Berry DP, Meaney WJ. Cow factors affecting the risk of clinical mastitis. Irish $J \mathrm{Ag}$ and Food Research. (2005) 44:147-56. Available online at: http://hdl. handle.net/11019/463

38. Barkema HW, Schukken YH, Zadoks RN. Invited review: the role of cow, pathogen, and treatment regimen in the therapeutic success of bovine Staphylococcus aureus mastitis. J Dairy Sci. (2006) 89:187795. doi: $10.3168 /$ jds.S0022-0302(06)72256-1

39. Roberson JR, Warnick LD, Moore G. Mild to moderate clinical mastitis: efficacy of intramammary amoxicillin, frequent milkout, a combined intramammary amoxicillin, and frequent milk-out treatment versus no treatment. J Dairy Sci. (2004) 87:583-92. doi: 10.3168/jds.S0022-0302(04)73200-2

40. Schukken YH, Bennett GJ, Zurakowski MJ, Sharkey HL, Rauch BJ, Thomas MJ, et al. Randomized clinical trial to evaluate the efficacy of a 5-day ceftiofur hydrochloride intramammary treatment on nonsevere gram-negative clinical mastitis. J Dairy Sci. (2011) 94:6203-15. doi: 10.3168/jds.2011-4290

41. Persson Y, Katholm J, Landin H, Mork MJ. Efficacy of enrofloxacin for the treatment of acute clinical mastitis caused by Escherichia coli in dairy cows. Vet Rec. (2015) 176:673. doi: 10.1136/vr.102667

42. Wraight MD. A comparative efficacy trial between cefuroxime and cloxacillin as intramammary treatments for clinical mastitis in lactating cows on commercial dairy farms. New Zeal Vet J. (2003) 51:2632. doi: $10.1080 / 00480169.2003 .36326$

43. McDougall S. Intramammary treatment of clinical mastitis of dairy cows with a combination of lincomycin and neomycin, or penicillin and dihydrostreptomycin. New Zeal Vet J. (2003) 51:111-6. doi: 10.1080/00480169.2003.36349

44. Taponen S, Dredge K, Henriksson B, Pyyhtia AM, Suojala L, Junni R, et al. Efficacy of intramammary treatment with procaine penicillin $G$ vs. procaine penicillin $G$ plus neomycin in bovine clinical mastitis caused by penicillin-susceptible, gram-positive bacteria - a double blind field study. $J$ Vet Pharmacol Therap. (2003) 26:193-8. doi: 10.1046/j.1365-2885.2003.00473.x

45. Sérieys F, Raguet Y, Goby L, Schmidt H, Friton G. Comparative efficacy of local and systemic antibiotic treatment in lactating cows with clinical mastitis. J Dairy Sci. (2005) 88:93-9. doi: 10.3168/jds.S0022-0302(05)72666-7

46. Taponen S, Jantunen A, Pyorala E, Pyorala S. Efficacy of targeted 5-day combined parenteral and intramammary treatment of clinical mastitis caused by penicillin-susceptible or penicillin-resistant Staphylococcus aureus. Acta Vet Scand. (2003) 44:53-62. doi: 10.1186/1751-0147-44-53

47. Bradley AJ, Green MJ. Factors affecting cure when treating bovine clinical mastitis with cephalosporin-based intramammary preparations. J Dairy Sci. (2009) 92:1941-53. doi: 10.3168/jds.2008-1497

48. Swinkels JM, Cox P, Schukken YH, Lam TJGM. Efficacy of extended cefquinome treatment of clinical Staphylococcus aureus mastitis. J Dairy Sci. (2013) 96:4983-92. doi: 10.3168/jds.2012-6197

49. Kalmus P, Simojoki H, Orro T, Taponen S, Mustonen K, Holopainen J, et al. Efficacy of 5-day parenteral versus intramammary benzylpenicillin for treatment of clinical mastitis caused by gram-positive bacteria susceptible to penicillin in vitro. J Dairy Sci. (2014) 97:2155-64. doi: 10.3168/jds. 2013-7338

50. Truchetti G, Bouchard E, Descôteaux L, Scholl D, Roy JP. Efficacy of extended intramammary ceftiofur therapy against mild to moderate clinical mastitis in Holstein dairy cows: a randomized clinical trial. Can J Vet Res. (2014) 78:31-7. 
51. Cortinhas CS, Tomazi T, Zoni MSF, Moro E, dos Santos MV. Randomized clinical trial comparing ceftiofur hydrochloride with a positive control protocol for intramammary treatment of nonsevere clinical mastitis in dairy cows. J Dairy Sci. (2016) 99:5619-28. doi: 10.3168/jds.2016-10891

52. Viveros M, Lopez-Ordaz R, Gutierrez L, Miranda-Calderon JE, Sumano H. Efficacy assessment of an intramammary treatment with a new recrystallized enrofloxacin vs ceftiofur and parenteral enrofloxacin in dairy cows with nonsevere clinical mastitis. J Vet Pharmacol Ther. (2018) 41:e19. doi: $10.1111 /$ jvp. 12441

53. McDougall S, Clausen L, Hintukainen J, Hunnam J. Randomized, controlled, superiority study of extended duration of therapy with an intramammary antibiotic for treatment of clinical mastitis. J Dairy Sci. (2019) 102:437686. doi: 10.3168/jds.2018-15141

54. McDougall S, Arthur DG, Bryan MA, Vermunt JJ, Weir AM. Clinical and bacteriological response to treatment of clinical mastitis with one of three intramammary antibiotics. $N$ Z Vet J. (2007) 55:161-70. doi: 10.1080/00480169.2007.36762

55. Schukken YH, Zurakowski MJ, Rauch BJ, Gross B, Tikofsky LL, Welcome FL. Noninferiority trial comparing a first-generation cephalosporin with a thirdgeneration cephalosporin in the treatment of nonsevere clinical mastitis in dairy cows. J Dairy Sci. (2013) 96:6763-74. doi: 10.3168/jds.2013-6713

56. Vasquez AK, Nydam DV, Capel MB, Ceglowski B, Rauch BJ, Thomas MJ, et al. Randomized noninferiority trial comparing 2 commercial intramammary antibiotics for the treatment of nonsevere clinical mastitis in dairy cows. $J$ Dairy Sci. (2016) 99:8267-81. doi: 10.3168/jds.2016-11258

57. Bryan MA, Hea SY, Mannering SA, Booker R. Demonstration of non-inferiority of a novel combination intramammary antimicrobial in the treatment of clinical mastitis. New Zeal Vet J. (2016) 64:33742. doi: 10.1080/00480169.2016.1210044

58. Tomazi T, Lopes TAF, Masson V, Swinkels JM, Santos MV. Randomized noninferiority field trial evaluating cephapirin sodium for treatment of nonsevere clinical mastitis. J Dairy Sci. (2018) 101:7334-47. doi: 10.3168/jds.2017-14002
59. Winder CB, Sargeant JM, Hu D, Wang C, Kelton DF, Godkin MA, et al. Comparative efficacy of antimicrobials for treatment of clinical mastitis in lactating dairy cattle: a systematic review and network meta-analysis. Anim Health Res Rev. (2019) 20:229-46. doi: 10.1017/S1466252319000318

60. Ruegg PL. Mastitis, detection, diagnosis and management. J Dairy Sci. (2017).

61. Hillerton JE, Kliem KE. Effective treatment of Streptococcus uberis clinical mastitis to minimize the use of antibiotics. J Dairy Sci. (2002) 85:100914. doi: 10.3168/jds.S0022-0302(02)74161-1

62. Oliver SP, Almeida RA, Gillespie BE, Headrick SJ, Dowlen HH, Johnson DL, et al. Extended ceftiofur therapy for treatment of experimentally-induced Streptococcus uberis mastitis in lactating dairy cattle. J Dairy Sci. (2004) 87:3322-9. doi: 10.3168/jds.S0022-0302(04)73468-2

63. Piaggio G, Elbourne DR, Altman DG, Pocock SJ, Evans SJW, Grp C. Reporting of noninferiority and equivalence randomized trials - an extension of the CONSORT Statement. JAMA-J Am Med Assoc. (2006) 295:115260. doi: 10.1001/jama.295.10.1152

64. Philpot WN. Role of therapy in mastitis control. J Dairy Sci. (1969) 52:70813. doi: $10.3168 /$ jds.S0022-0302(69)86633-6

65. Andreani NA, Carraro L, Zhang L, Vos M, Cardazzo B. Transposon mutagenesis in Pseudomonas fluorescens reveals genes involved in blue pigment production and antioxidant protection. Food Microbiol. (2019) 82:497-503. doi: 10.1016/j.fm.2019.03.028

Conflict of Interest: The author declares that the research was conducted in the absence of any commercial or financial relationships that could be construed as a potential conflict of interest.

Copyright $\odot 2021$ Ruegg. This is an open-access article distributed under the terms of the Creative Commons Attribution License (CC BY). The use, distribution or reproduction in other forums is permitted, provided the original author(s) and the copyright owner(s) are credited and that the original publication in this journal is cited, in accordance with accepted academic practice. No use, distribution or reproduction is permitted which does not comply with these terms. 